\title{
Embracing Technology
}

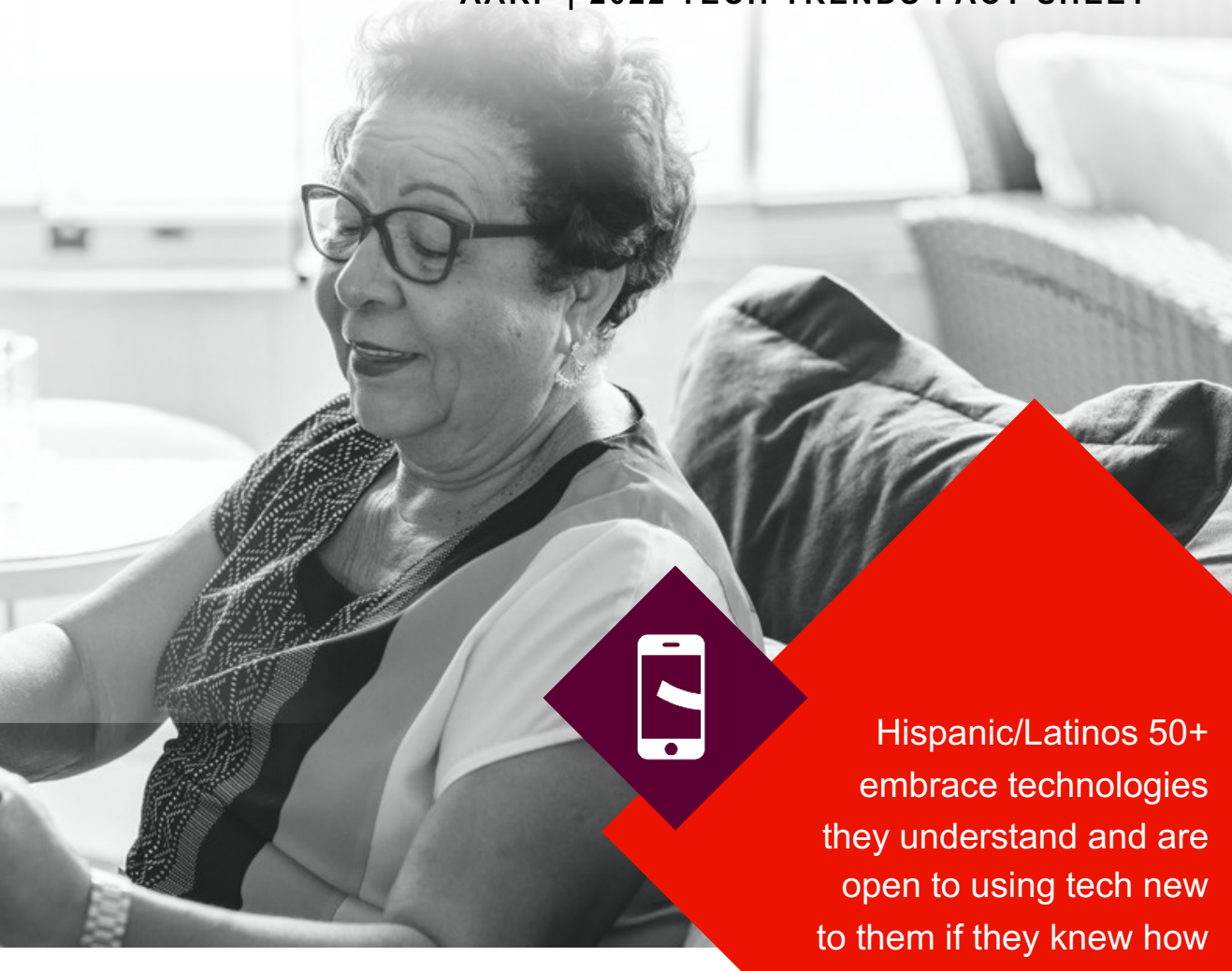

\section{Tech trends identified during the height of the pandemic of COVID-19 continue to hold among Hispanic/Latinos 50+}

Hispanic/Latinos 50-plus continue to spend on tech devices and frequently use them once they know-how, but they remain cautious when they don't. From using smartphones to connect with friends and family via text or video chat, to streaming programming, making purchases, or banking online, Hispanics 50-plus have embraced technology to entertain and help manage life. Awareness is key to increasing their comfort level with certain tech devices or services, resulting in more Hispanic/Latinos 50-plus adopting newer technology like wearables, home assistants, and smart home devices.

\section{Hispanic/Latinos 50+ continue to embrace new tech devices}

Hispanic/Latinos 50-plus ownership rate of newer technology continues to increase in 2021 where home assistants $(11 \%, 2019 ; 28 \%, 2020 ; 35 \%, 2021)$ and smart home devices $(9 \%$, 2019; 21\%, 2020; 27\%, 2021) saw ownership increase threefold from 2019, while wearables ownership doubled (12\%, 2019; 24\%, 2020; 26\%, 2021). Ownership of smartphones (86\%, $2020 ; 84 \%, 2021)$, tablets $(59 \%, 2020 ; 57 \%, 2021)$, and smart TVs $(67 \%, 2020 ; 70 \%, 2021)$ remains steady from last year. The increase in ownership of newer technology is encouraging since most (57\%) state they usually try a new tech trend after it's been around for a while. This signals Hispanic/Latinos 50-plus might perceive wearables, home assistants, and smart home devices as tech that has been around for a while or perhaps have embraced tech after others have introduced them to it. When presented with cutting edge technology, one-quarter express being interested in clothing that responds to the body and environment and keeps you warm or cool $(26 \%)$, and automated yard or house cleaning devices like robotic vacuums or lawnmowers $(23 \%)$, one in five (20\%) express interest on in-home devices like smart toilets, and one in seven (14\%) in driverless cars.

\section{Hispanics 50+ have embraced technology to entertain and help manage life}




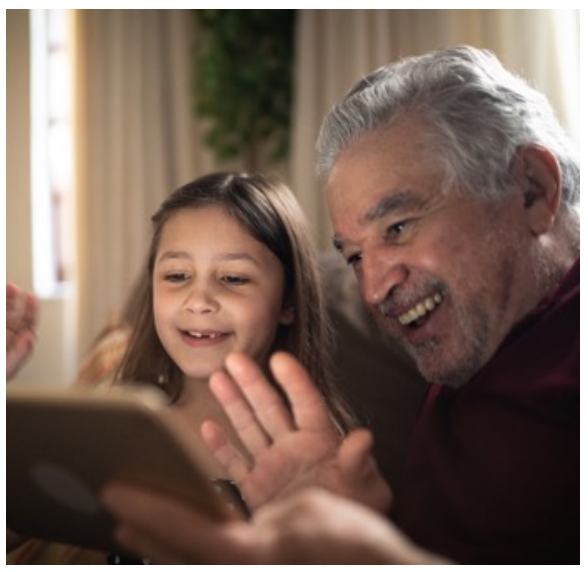

\section{Tech spending remains high among Hispanic/Latinos $50+$}

Spending on technology among Hispanic/Latinos, in general, continues to be higher in 2021 than before the COVID-19 pandemic, although it did decline slightly from last year ( $\$ 430$ in $2019, \$ 1,164$ in 2020, and $\$ 938$ in 2021). The top tech devices purchased in 2021 by Hispanic/Latinos 50-plus were smartphones (30\%), smartphone accessories (28\%), and smart TVs (25\%). Purchase of wearables (5\%, 2019; 11\%, 2020; 8\%, 2021), home assistants (5\%, 2019; 13\%, 2020; 9\%, 2021), and smart home devices (5\%, 2019; 13\%, 2020; 6\%, 2021) all fell in 2021 after a significant increase in 2020, even though ownership continues to increase among Hispanic/Latinos 50-plus. An increase in ownership among newer tech such as wearables, home assistant, and smart home devices with a decline in purchasing could mean they are being gifted these devices, and once they own one, they embrace them as most use them daily (84\%, smart home technology; $74 \%$, wearables; $60 \%$, home assistants).

\section{Hispanic/Latinos $50+$ technology spend}

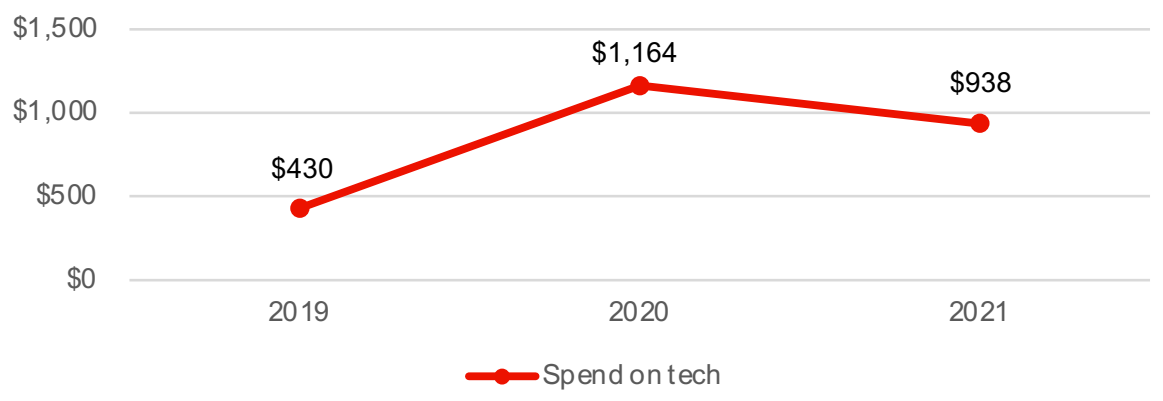

\section{$71 \%$}

of Hispanic/Latinos 50+ made a tech purchase in 2021

$54 \%$ $77 \%$ 2019

\section{Comfort is key to increasing comfort with technology}

Although roughly two in five (39\%) think technology is not designed with all ages in mind, most do feel comfortable with technology that has been around a long time, like the Internet (69\%), smartphones (64\%), computers (61\%) and tablets (54\%) even when almost one-half $(48 \%)$ say they are not confident their online activity remains private when using these devices. Two in five (42\%) say the same when using home assistants and smart home devices and this distrust has increased from last year (34\% in 2020).

Comfort levels with technology drop a bit with video chatting (36\%) and even more so with home assistants (25\%), and significant differences are observed in comfort levels between Hispanics 50-plus who own a device and Hispanics 50-plus overall for some devices like tablets (25 percentage point difference) and home assistants (22 percentage point difference). This difference in comfort level with tablets is especially interesting as they are very similar to a smartphone, only bigger, sharing most features and functionalities, however, the difference in comfort level for a smartphone is only seven percentage points.

\section{Hispanic/Latinos $50+$ comfortable with each technology}

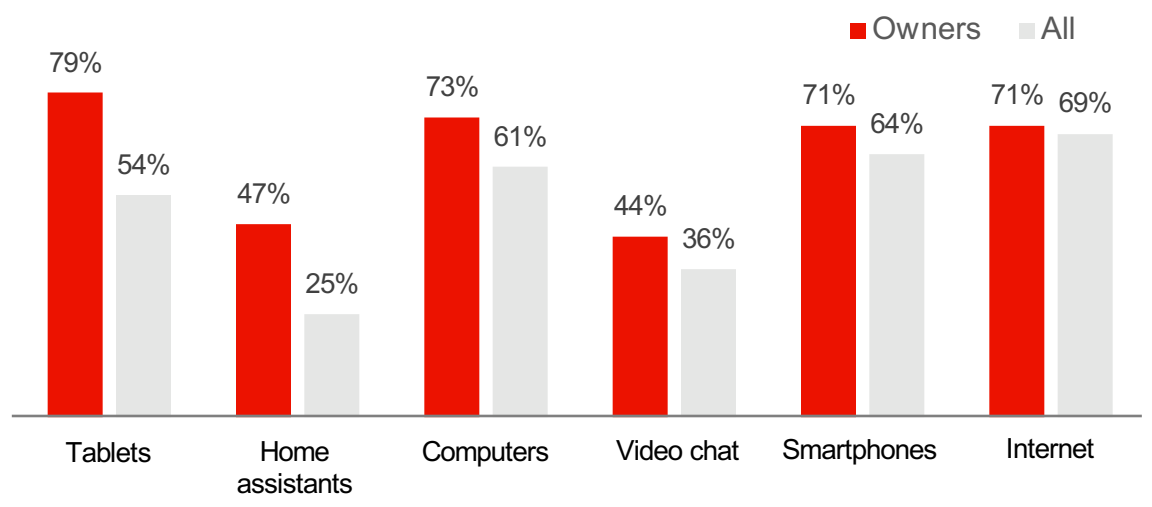

Two-in-five (41\%) Hispanic/Latinos 50+ would use technology more in their daily life if they knew how.

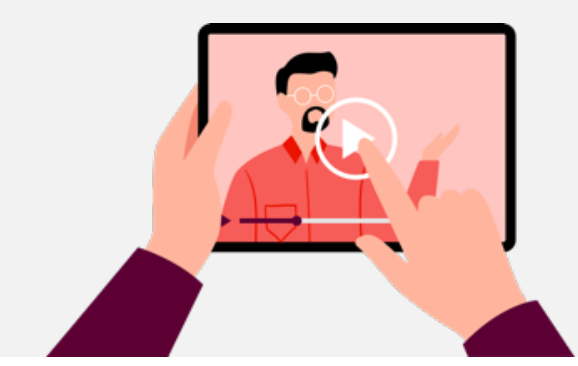


From entertainment to daily tasks, smartphones are an essential device for Hispanics $50+$

With a majority of Hispanic/Latinos 50 -plus being both familiar and comfortable using smartphones, it is not surprising to see it continues to be the tech device of choice, with four in five (84\%) owning one and nearly all (98\%) using it daily to complete a myriad of tasks. Like others their age, Hispanic/Latinos 50-plus turned to their devices during the COVID-19 pandemic to perform tasks traditionally done in-person, like banking (65\%) and shopping (59\%) and continue to do so in 2021 . Four in five (79\%) use their smartphone to get traffic information and directions and more than one-half (55\%) use their smartphones to comparison shop, likely making them into more savvy shoppers. They also spend their time on their smartphones surfing the internet (77\%), getting their news (71\%), accessing social media (61\%), and engaging with healthcare providers $(51 \%)$.

\section{How Hispanic/Latinos $50+$ use their smartphones}

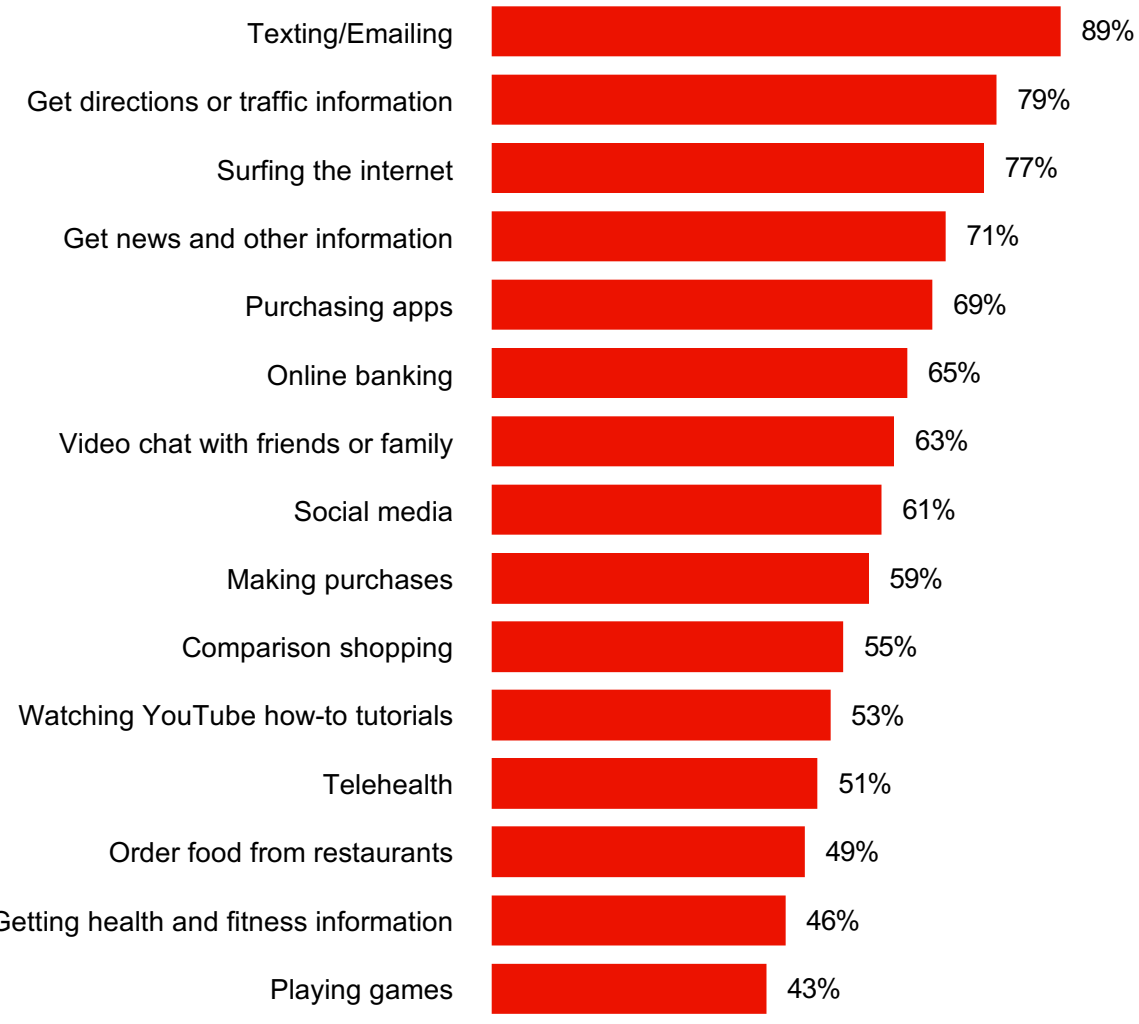

\section{Lack of tech know-how keeps many Hispanic/Latinos 50+ from learning new skills, tracking their health, \& connecting with others}

Even though most Hispanic/Latinos 50-plus frequently use tech devices, like smartphones, to perform daily tasks, there are other helpful devices to use and tasks they would be more motivated to do if only they knew how to use the relevant technology. For example, seven in ten $(69 \%)$ are motivated by tech to connect with others, while one-half (52\%) would do so to help them stay healthy, and nearly as many (48\%) would do so for entertainment purposes, like listening to podcasts or streaming shows. Only one in five (18\%) claim they have pursued a passion or interest or built a new skill that was supported by the use of technology, yet more than twice that (45\%) would like to use technology to learn a new skill.

\section{Top 15 mobile apps used by Hispanic/Latinos $\mathbf{5 0 +}$}

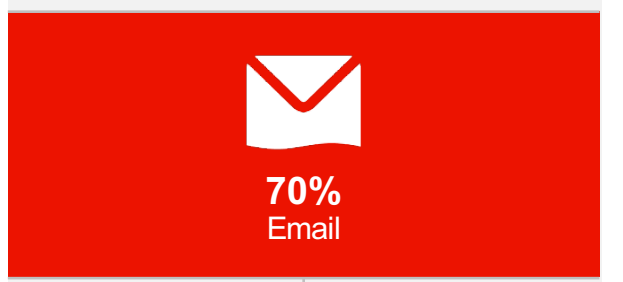

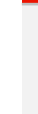

\begin{tabular}{|c|c|}
\hline $\begin{array}{c}68 \% \\
\text { Photos }\end{array}$ & $\begin{array}{c}62 \% \\
\text { Internet browser }\end{array}$ \\
\hline $\begin{array}{l}57 \% \\
\text { Weather }\end{array}$ & $\begin{array}{c}56 \% \\
\text { Maps and navigation }\end{array}$ \\
\hline $\begin{array}{c}55 \% \\
\text { Social media }\end{array}$ & $\begin{array}{l}48 \% \\
\text { Retail shopping }\end{array}$ \\
\hline $\begin{array}{c}44 \% \\
\text { Finance/banking }\end{array}$ & $\begin{array}{l}41 \% \\
\text { Music }\end{array}$ \\
\hline $\begin{array}{l}38 \% \\
\text { Calendar }\end{array}$ & $\begin{array}{l}38 \% \\
\text { Video chat }\end{array}$ \\
\hline $\begin{array}{c}x \\
\widehat{X} \boldsymbol{X} \\
32 \% \\
\text { Games }\end{array}$ & $\begin{array}{c}31 \% \\
\text { Video or } \\
\text { movie streaming }\end{array}$ \\
\hline $\begin{array}{c}29 \% \\
\text { News/magazines }\end{array}$ & $\begin{array}{c}\curvearrowright \\
23 \% \\
\text { Home assistant }\end{array}$ \\
\hline
\end{tabular}




\section{Most Hispanic/Latinos 50+ now stream programming and those who don't, wish they could}

Even though more than one-half (56\%) of Hispanic/Latinos 50 -plus consider the cost of high-speed internet to be an issue, streaming programming continues to be popular among them as three in five (62\%) do so, and among those who don't, one-quarter (32\%) wish they knew how to. Seven in ten (70\%) own a smart TV and one-quarter (32\%) stream programming daily. On average, this cohort subscribes to three streaming channels, although over one-half (56\%) feel they pay too much for such services and two in five (42\%) think they need multiple streaming channels to have enough content from which to choose. The most popular channels are Netflix (74\%), Amazon Prime Video (52\%), Disney+ (31\%), and HBO Max (31\%), the latter doubling in Hispanic/Latinos 50-plus subscribers (16\% in 2020). Yet, one-third (34\%) say they have trouble finding what to watch and where.
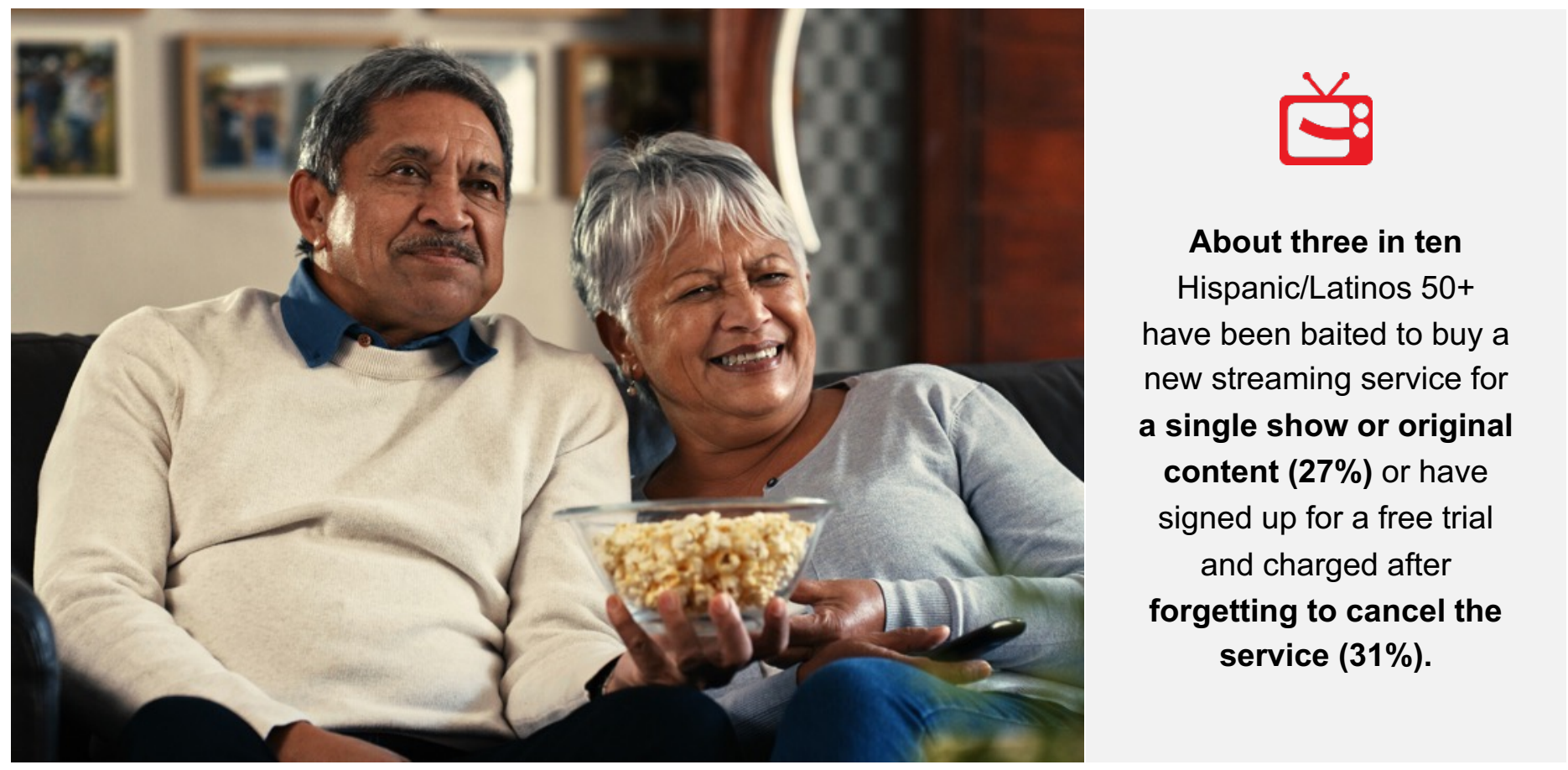

\section{Implications}

One hurdle preventing Hispanic/Latinos 50-plus from adopting technology with which they are not familiar is lack of knowledge of different tech devices and what they do. To create awareness and comfort among this group about products like wearables, home assistants, and smart home devices, specific information about what these products can do for them, and how they can easily learn to use them to improve their daily lives or tasks they perform is essential.

Two in five (39\%) Hispanic/Latinos 50-plus feel tech is not designed with all ages in mind, and, at the same time, with this cohort's spend on technology being significant, there is an opportunity to address their needs to increase the adoption and use of technology.

The adoption and use of smartphones is an example of Hispanic/Latinos 50-plus embracing tech. Hispanic/Latinos 50-plus can be found checking the news, on social media, on a retailer's online website, or simply surfing the net, so there is a myriad of potential touchpoints for companies to engage with them through technology. They have an interest in trying new technology with which they are comfortable, giving them significant buying power.

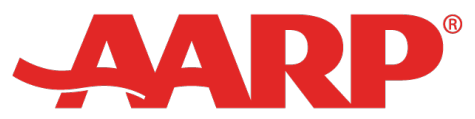

For more information, contact Brittne Kakulla, bkakulla@aarp.org.

For media inquiries, contact media@aarp.org.

DOI: https://doi.org/10.26419/res.00493.012 